\title{
Processos estruturais do manejo e conservação da fauna silvestre em risco de extinção: casos amazônicos
}

\author{
Structural processes of management and conservation of \\ wildlife at risk of extinction: Amazonian cases
}

\author{
Wagner de Deus Mateus ${ }^{\mathrm{a}}$ \\ Maria Inês Gasparetto Higuchi ${ }^{\text {b }}$
}

${ }^{a}$ Doutor em Ciências do Ambiente e Sustentabilidade na Amazônia, Universidade Federal do Amazonas, Professor, Secretaria de Estado de Educação e Qualidade do Ensino do Amazonas, Manaus, AM, Brasil. End. Eletrônico: wagnermthus@gmail.com

${ }^{b}$ Pesquisadora do Instituto Nacional de Pesquisas da Amazônia, Laboratório de Psicologia e Educação Ambiental, Manaus, AM, Brasil. End. Eletrônico: higuchi.mig@gmail.com

doi:10.18472/SustDeb.v9n3.2018.18580

Recebido em 17.05.2018

Aceito em 18.09.2018

ARTIGO - VARIA

\begin{abstract}
RESUMO
O presente trabalho analisa a estrutura e processos envolvidos na conservação e manejo de duas espécies da fauna silvestre amazônica em risco de extinção. A pesquisa abordou o contexto dos programas de conservação do Gavião-Real (Harpia harpyja) e do tracajá (Podocnemis unifilis) desenvolvidos com comunidades no interior do estado do Amazonas. $O$ estudo baseou-se em uma pesquisa documental com análise de conteúdo. As análises permitiram aglutinar processos e estratégias envoltos na conservação dessas duas espécies-bandeira, baseados em manejo comunitário participativo. Verificouse que as práticas conservacionistas para ambas as espécies são distintas, mas indicam dimensões comuns e propositivas, tais como: participação, colaboração, comunicação e educação.
\end{abstract}

Palavras-chave: Educação ambiental; Práticas conservacionistas; Manejo comunitário; Manejo participativo.

\begin{abstract}
The present work analyzes the structure and processes involved in the conservation and management of two species of the Amazonian wild fauna in danger of extinction. The research approached the context of the conservation programs of the Harpy eagle (Harpia harpyja) and the yellow-spotted Amazon river turtle (Podocnemis unifilis) developed within interior communities of the state of Amazonas. The research was based on a documentary research with content analysis. The analyzes allowed to agglutinate processes and strategies involved in the conservation of these two flagship species, based on participatory community management. It has been found that conservation practices for both species are distinct but indicate common and propositional dimensions such as participation, collaboration, communication and education.
\end{abstract}

Keywords: Environmental education; Conservation practices; Community management; Participative management. 


\section{INTRODUÇÃO}

Nos últimos anos diversos trabalhos vêm evidenciando a perda da biodiversidade global (PEREIRA et al., 2010; BARNOSKY et al., 2011; DIRZO et al., 2014; KUGLER, 2014; SEDDON et al., 2014; WWF, 2014a). Para demonstrar isso, estima-se que existam 2 milhões de espécies conhecidas de um total que flutua entre 5 à 9 milhões existentes. No entanto, atualmente esse total sofre uma taxa de extinção da ordem de 10 mil espécies ao ano (WWF, 2014b).

A taxa de extinção, quando analisada em séries históricas, mostra haver um processo denominado defaunação (DIRZO et al., 2014). Esse fenômeno compreende a perda de espécies de populações de animais selvagens, e, por consequência, declínios da abundância de indivíduos, considerando os efeitos da caça e o desmatamento.

Na defaunação os impactos são diretos nas funções e serviços ecossistêmicos, como a polinização, o controle biológico, alteração no ciclo dos nutrientes e decomposição, qualidade da água, saúde humana, assim como impactos sobre os padrões evolutivos das espécies, animal ou vegetal (GALETTI; DIRZO, 2013; HARRISON et al., 2013; SEDDON et al., 2014). Na atualidade, discute-se que esse contexto defaunativo é uma característica do período denominado de Antropoceno. Nesse período histórico, a espécie humana teria se tornado um agente geológico, ou seja, um agente transformador de mundo, modificando os ecossistemas do planeta de acordo com as suas necessidades de sobrevivência (STEFFEN et al., 2007; ELLIS et al., 2013).

As formas de frear a defaunação são diversas, e, em sua maioria, conectam-se ao eixo da conservação ambiental. Atualmente são discutidas duas perspectivas de conservação, a in situ e ex situ. A primeira refere-se às ações voltadas ao local de origem dos seres vivos, seu habitat natural. A segunda, condiz com os processos que envolvem a conservação fora desse habitat, como, por exemplo, os jardins zoológicos, bancos de germoplasmas, entre outros.

Tanto numa quanto noutra, é possível encontrar potencialidades e dificuldades, já que "a conservação ex situ quase sempre complementa as ações de conservação in situ" (GASTAL; SARAGOUSSI, 2008, p. 49). Enquanto a última tem um apelo estético e romântico, a segunda possibilita um acompanhamento e observação mais controlada. Desse modo, o enfoque dos casos pesquisados refere-se à conservação in situ de espécies-bandeira desenvolvidas por programas conservacionistas na região amazônica.

As espécies-bandeira (flagship species) são aquelas que possuem um apelo simbólico, estético e emblemático (ENTWISTLE, 2002; CARO et al., 2004; BOWEN-JONES; CLUCAS et al., 2008; HOME et al., 2009; BARUA et al., 2011; SMITH et al., 2012), e são consideradas espécies porta-vozes para facilitar a conexão afetiva entre humano e não humanos. Outra nomenclatura conservacionista designa espécies guarda-chuva (umbrela species) quando essas estão ligadas à conservação de extensas áreas vegetais, não apenas seu habitat, suas considerações de escolha são de ordem técnica (SIMBERLOFF, 1998; ROBERGE; ANGELSTAM, 2004; CARO, 2010). O foco desta pesquisa foram as espécies-bandeira gaviãoreal (Harpia harpyja) e tracajá (Podocnemis unifilis).

Dessa forma, o objetivo do estudo foi analisar a estrutura e o funcionamento do manejo e conservação da fauna silvestre em dois programas conservacionistas: o primeiro denominado Manejo Comunitário de Quelônios no Médio Rio Amazonas e Juruá - "Pé-de-Pincha" e o segundo, o Programa de Conservação do Gavião-Real (PCGR). Para tanto, utilizou-se uma pesquisa documental com análise de conteúdo (BARDIN, 2016) para caracterizar o contexto ecológico das espécies, as relações humanos e fauna, assim como identificar quais estruturas subsidiam o funcionamento dos programas e as dimensões necessárias para as práticas conservacionistas.

De acordo com essa técnica de análise, tem-se primeiramente a fase de pré-análise, na qual foi definido o corpus de análise, proveniente das leituras flutuantes dos documentos pesquisados. Foram coletados e analisados relatórios técnicos, folders, cartilhas, assim como notícias nos websites institucionais dos programas, e a produção acadêmica, teses, dissertações, livros e artigos científicos indexados em periódicos e eventos nacionais e internacionais. Na fase de exploração do material, foram definidos os conteúdos para unidades de registro (UR) e contexto (UC), o modo de contagem, quanto à presença/ 
ausência, ordem e coocorrência, e a forma de categorização do tipo semântica e léxica. No tratamento dos resultados, optaram-se por inferências específicas a partir das significações dos enunciados. Dessa forma, foram utilizadas as técnicas de análise categorial/temática.

A estrutura do artigo está pautada em três categorias construídas no âmbito socioambiental presente nos dois programas. O primeiro refere-se aos aspectos biológicos e ecológicos de cada espécie, assim como o seu estado de conservação. Na sequência há a caracterização da conservação, abordando quais ações e atividades foram construídas pelos programas para conservar ou manejar as duas espécies de acordo com o contexto socioambiental. E, por fim, as análises das atividades conservacionistas, onde foi possível dialogar com a literatura científica específica acerca das orientações e experiências já desenvolvidas em outros locais e momentos históricos. E, finalmente, uma seção com a síntese das análises.

As atividades em análise referem-se àquelas realizadas nas comunidades ribeirinhas de Piraí e Tucumanduba no município de Barreirinha (AM) (Figura 1), e em duas comunidades no Assentamento Vila Amazônia, Santa Clara do Quebrinha e São Sebastião do Quebra, no município de Parintins (A) (Figura 2), ambas no Estado do Amazonas.

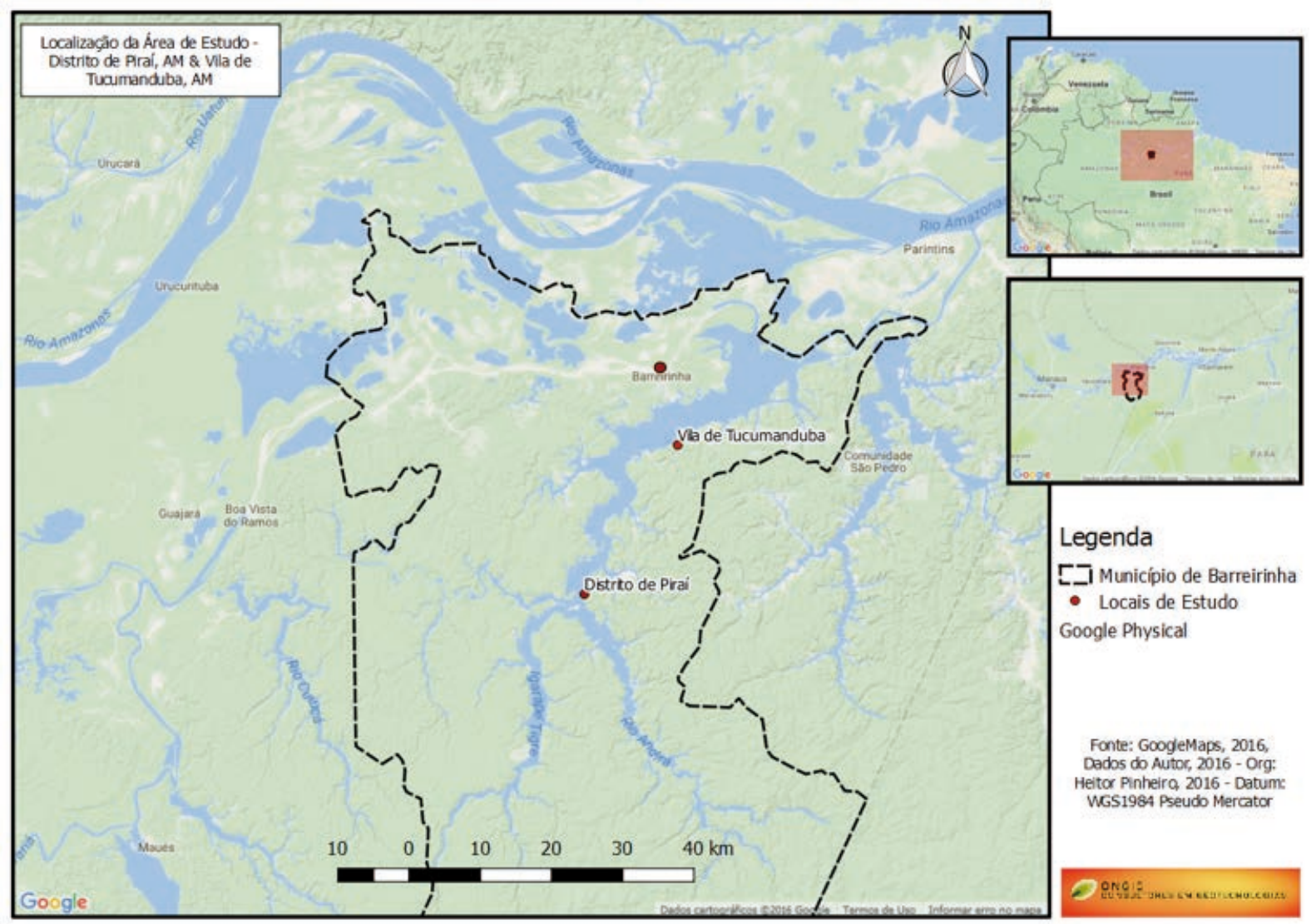

Figura 1 - Localização das comunidades ribeirinhas integrantes da conservação do tracajá

Fonte: Heitor Pinheiro (2016). 


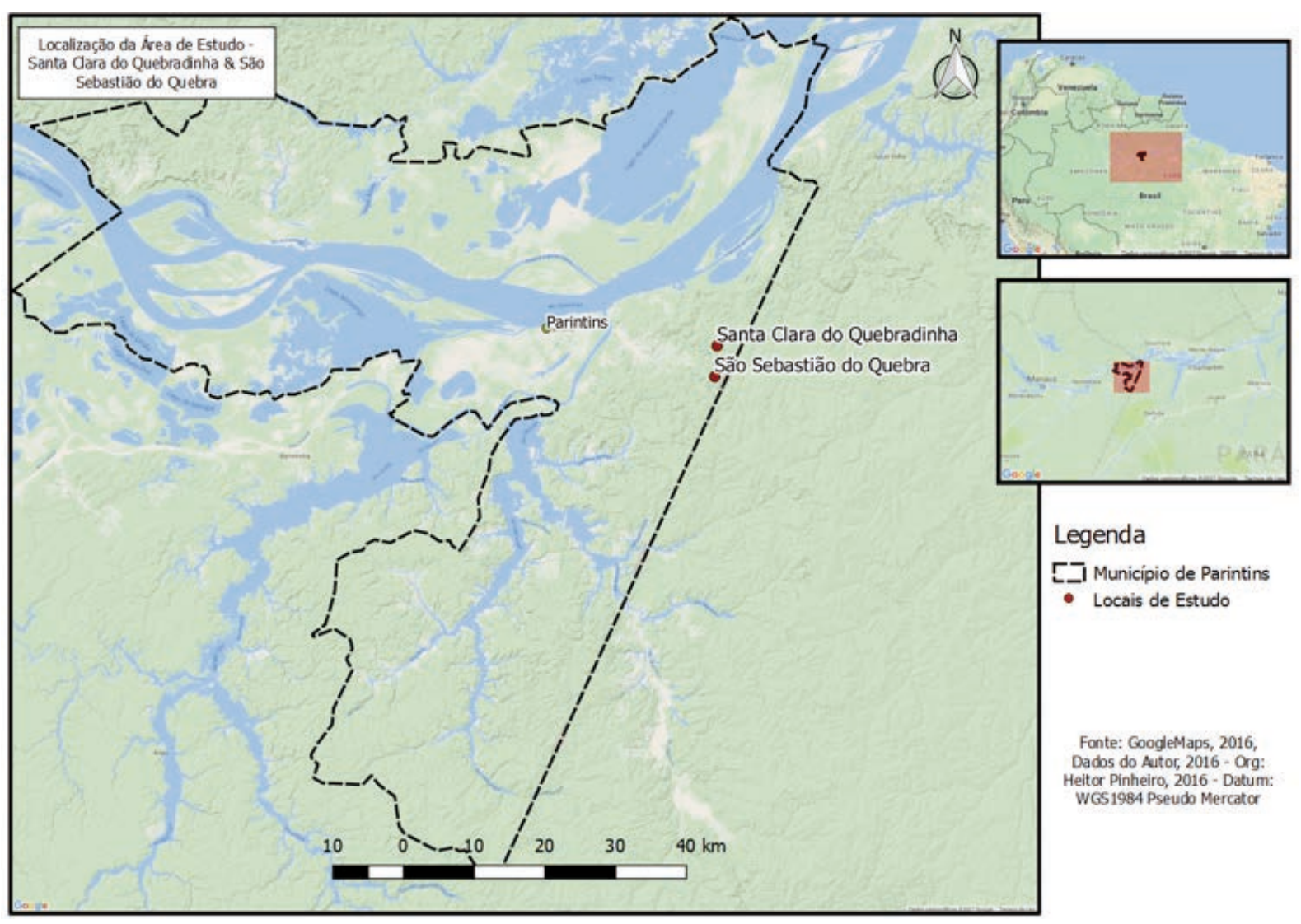

Figura 2 - Localização das comunidades no assentamento rural integrantes da conservação do gavião-real.

Fonte: Heitor Pinheiro (2016)

\section{NA TERRA E NO AR: O CASO DA CONSERVAÇÃO DO GAVIÃO-REAL (Harpia harpyja)}

O gavião-real, Harpia harpyja (Linnaeus, 1758) ou uiraçu-verdadeiro é uma ave representante da família Accipitridae, a maior na Mesoamérica e mais poderosa no mundo (SIGRIST, 2009). Na região Neotropical, é considerado predador de topo no dossel dos bosques (FERGUSON-LEES; CHRISTIE, 2001; VARGAS et al., 2006). A primeira descrição da harpia foi feita por naturalistas europeus ainda no século XVIII, quando a espécie habitava a maioria das grandes florestas desde o sul do México até o norte da Argentina (SANAIOTTI, 2010).

\subsection{ASPECTOS BIOLÓGICOS E ECOLÓGICOS DA ESPÉCIE}

A ave na fase adulta possui duas penas evidentes no penacho; uma faixa de penas pretas no pescoço, e cabeça, lados do pescoço e garganta são cinza-claros. No dorso e parte superior das asas é preto, não há dimorfismo sexual quanto à coloração. Pode medir 1,05 metro de comprimento total do corpo, quando adulto pode apresentar até 2,05 metros de envergadura de asas. 0 macho adulto pode pesar 5,5 kg e a fêmea $8 \mathrm{~kg}$. Um filhote nasce a cada 2,5-3 anos. As garras (hálux) podem medir até $6 \mathrm{~cm}, \mathrm{uma}$ característica marcante de aves de rapina (FERGUSON-LEES; CHRISTIE, 2001; SANAIOTTI, 2010).

Atualmente, o gavião-real pode ser encontrado desde as florestas tropicais das terras baixas do sul do México e América Central às da América do Sul. Possuía distribuição mais ampla no Brasil, onde a espécie era muito abundante até a redução das florestas dessas regiões nos últimos 500 anos (AGUIARSILVA; SANAIOTTI, 2013; IUCN, 2016). 
Trata-se, portanto, de uma espécie escassamente distribuída, reduzindo-se a poucos casais em algumas regiões e em outras já é extinta. Atualmente, com a diminuição da população devido à caça e perda de habitat, o seu principal refúgio fica na América do Sul, na floresta tropical amazônica (AGUIARSILVA; SANAIOTTI, 2013; BANHOS, 2016). Os gaviões-reais identificados na Amazônia, mesmo com um hábito geralmente sedentário, costumam sair em busca de alimentos em áreas da América do Sul (FERGUSON-LEES; CHRISTIE, 2001), mesmo quando não se trata de alimentação.

A força e o porte físico do gavião-real caracteriza-o como uma ave de rapina (SICK, 1997; VARGAS et al., 2006). De acordo com o Plano de Ação Nacional para conservação de Aves de Rapina (PAN) (SOARES et al., 2008), essa nomenclatura é utilizada para identificar aves carnívoras de hábitos diurnos e noturnos que apresentam garras e bicos fortes utilizados para agarrar e matar as presas. Quanto ao status de conservação da espécie, a International Union for Conservation Nature (IUCN) (2016) classifica-o como "Near threatened" (NT) ou quase ameaçada, já para o ICMBio (2014), a espécie encontra-se "Vulnerável" (VU).

Desse estado de conservação é possível fazer um paralelo com o contexto alimentar local. Verifica-se que enquanto fonte nutritiva na Amazônia, há poucos relatos na literatura científica (SOARES et al., 2008; FREITAS et al., 2014), pois há outras fontes com maior volume de biomassa. Enquanto objeto para lazer e ostentação, a demanda advém do tráfico no mercado ilegal internacional financiado por colecionadores e criadores ilegais. Além da caça e tráfico, outros aspectos influenciam na redução na população da espécie, tais como conflitos e perseguições humanas.

Se por um lado a invasão de populações humanas nos habitats dos gaviões-reais é potencializada pela implantação de áreas para a criação de animais domésticos e a pecuária extensiva, de outro verificase como uma das consequências, a disponibilidade de presas não naturais, como galinhas, porcos, carneiros e mesmo o gado (SOARES et al., 2008; TRINCA et al., 2008; GUSMÃO et al., 2016).

Nesse contexto de conflito, o abate do gavião-real é, na visão de moradores locais, aceitável, para impedir futuros prejuízos. Estudos mostram que a relação entre prejuízos na criação de animais domésticos e a presença de gavião-real nas adjacências não se sustenta (AGUIAR-SILVA et al., 2014; MIRANDA, 2015). Miranda (2015) compilou dados de publicações científicas sobre padrões de predação da espécie e percebeu que as preguiças representam $50 \%$ da dieta, o restante advém de macacos da espécie Alouatta spp., Sapajus spp e Cebus spp.

Nesse contexto da relação entre humanos e gavião-real, ações como as desenvolvidas pelo Programa de Conservação do Gavião-Real (PCGR) do Instituto Nacional de Pesquisas da Amazônia tentam proteger a espécie a partir de estudo sobre a ecologia da ave, e envolvimento das populações locais mediante a educação ambiental. O PCGR iniciou suas atividades em 1997, após a descoberta do primeiro ninho da espécie em uma floresta de terra firme nas cercanias da cidade de Manaus (AM). Em 1999, o programa estabeleceu metas de ampliação da localização e o mapeamento de ninhos para estudar a biologia da espécie na Amazônia brasileira.

A consolidação da ampliação da área de registro no País se deu a partir de 2005 com o registro de um ninho do gavião-real na Mata Atlântica (RPPN Estação Veracel-BA) e outro em 2008 na Floresta Nacional de Carajás (PA). Em março de 2017, o programa comemorou 20 anos de existência e com a realização do Workshop Harpia reuniu inúmeras instituições de pesquisa, e adotou a nomenclatura de Programa de Conservação da Harpia.

\subsection{CARACTERIZAÇÃO DA CONSERVAÇÃO}

A missão do programa é promover a pesquisa e a conservação das grandes águias brasileiras em âmbito nacional e com vínculos institucionais fortalecidos, tendo como bandeira o gavião-real. Além da espécie, o programa também desenvolve estudos sobre o Morphnus guianensis (Daudin, 1800), conhecido como Uiraçu-falso e o Spizaetus ornatus (Duadin, 1800), também conhecido como gaviãode-penacho. 
A análise da estrutura do PCGR demonstrou uma articulação entre atividades voltadas à pesquisa, capacitação, reabilitação e sensibilização ambiental, desdobrando-se em ações específicas, organizadas em duas abordagens: a) técnica e b) socioeducativa. Na primeira constam ações, como telemetria, genética, dieta e reintegração da ave ao habitat local; na segunda, têm-se oficinas, práticas sustentáveis, valorização biocultural e mostras científicas.

\subsection{ANÁLISE DAS ATIVIDADES}

As atividades técnicas, como as de pesquisa e reabilitação, envolvem prioritariamente os pesquisadores, em sua maioria biólogos. São eles que coordenam as ações iniciais para conservação da espécie. No âmbito socioeducativo, tem-se a integração entre PCGR e comunidade para estudos, seja em nível genético, da espécie ou do ecossistema, mediante o envolvimento entre as duas partes.

Nessa última abordagem, as atividades comunicativas desenvolvidas pelos biólogos favorecem o desenvolvimento da chamada alfabetização ambiental. Esse processo vai além da conscientização e do aprendizado rotineiro, pois envolve pensamento crítico, integrando princípios e usando habilidades adquiridas para transformar o conhecimento em ação (BICKFORD et al., 2012). Bickford et al. (2012) citam que os próprios pesquisadores devem realizar as atividades educativas, buscando envolver qualquer público (escola, igrejas, acadêmicos ou não), utilizando os meios de comunicação disponíveis.

A criação e manutenção de diálogos entre cientistas e comunitários são chaves para alinhar as metas de ação, logo, a inserção de processos educativos é essencial na eficácia da conservação da biodiversidade, desde que haja o compartilhamento de responsabilidade, uma característica da gestão/ manejo ambiental (CARLSSON; BERKES, 2005; BERKES, 2009). Como exemplo de espaço de diálogo, citam-se as Mostras de Ciências realizadas ao longo de sete anos (2004-2010). As Mostras além de serem estratégias de divulgação ou popularização da ciência, foram úteis como momento para discutir, socializar e valorizar os saberes locais. As Mostras de 2004 a 2007 foram coordenadas pelo PCGR, já nas edições de 2008 a 2010, as próprias comunidades e escolas foram as organizadoras dos eventos.

O estudo de Carvalho et al. (2015) sobre as Mostras de Ciências, realizadas no Assentamento Vila Amazônia, evidenciou que os comunitários passaram a perceber a ciência como algo mais perto de seu cotidiano, pois podiam interagir com os cientistas. Nesses momentos, discutiam-se temas relacionais à tecnologia, saúde, uso dos recursos e conservação da natureza, proporcionando aos participantes uma experiência multidisciplinar e transformadora.

Aliadas à divulgação científica, as atividades do PCGR favoreceram a valorização da cultura local, traduzida pela realização da festa e dança do gavião-real. A utilização de aspectos culturais das comunidades locais é considerada força motriz e imprescindível para a eficácia da conservação da biodiversidade (PRIMACK; RODRIGUES, 2001; BOWEN-JONES; ENTWISTLE, 2002; SILVA, 2015; ADOM, 2016). Portanto, estratégias conservacionistas que não consideram aspectos culturais das pessoas envolvidas podem estar sendo potencialmente excludentes.

Adom (2012), ao pesquisar a participação local na conservação, verificou que em países como Brasil, China, Japão, Índia, Tanzânia, Angola e Quênia onde as populações locais foram incorporadas, e suas práticas culturais incentivadas, houve um aumento significativo da biodiversidade foco da conservação. Outra dimensão explorada junto ao PCGR foi o incentivo ao turismo sustentável com foco na observação dos locais de nidificação.

De acordo com Silva e Sanaiotti (2007), essa ação teria como resultado o fortalecimento, entre outros, da divulgação em nível regional para a sociedade valorizar o patrimônio natural local, ampliando os valores de manutenção de áreas nativas, assim como estimular e apoiar a criação de Unidades de Conservação. Com isso, seria possível receber visitantes e subsidiar o ecoturismo, gerando melhoria da qualidade de vida da comunidade por meio de práticas de desenvolvimento sustentável e sensibilização ambiental. Neste caso, Rotemberg et al. (2009) discutem que atividades dessa categoria necessitam estar planejadas em acordo com a comunidade e serem baseadas a longo prazo, pois, senão, podem representar apenas atividades exógenas sem benefícios aos locais. 
Estudos mostram que programas de conservação, não apenas de aves, mas da biodiversidade como um todo, tornam-se eficazes quando aliam pesquisa, participação comunitária, capacitação e geração de renda (WALPOLE; LEADER-WILLIAMS, 2002; VERÍSSIMO et al., 2009; ROTEMBERG et al., 2009; SEKERCIOG 'LU, 2012; ADOM, 2016). Nesse contexto de múltiplas estratégias, os processos educativos, além de serem meios de divulgação e informação, surgem como estrutura ligante e fortalecedor da integração entre programa de conservação e comunidade.

Nos programas de conservação, os processos educativos constituem a educação ambiental ou comunitária voltados, em primeira instância, ao âmbito conservacionista (CURTI; VALDEZ, 2009; ROTEMBERG et al., 2009). Dessa forma, um dos principais desafios é capturar a imaginação e o interesse das populações locais de forma a estimular a cooperação e a ação de conservação (MILLER, 2005). Portanto, quanto mais diversificadas forem as estratégias, mais sólida pode ser a participação comunitária.

As analises mostram que a estratégia utilizada pelo PCGR é aliar as comunidades tradicionais do entorno dos ninhos, assim como solidificar as parcerias com instituições federais, estaduais e privadas para favorecer a divulgação da importância da preservação ambiental e os resultados alcançados. E com isso a conservação como base para a sensibilização ambiental torna-se uma estratégia para fugir do erro de atribuir apenas à educação a responsabilidade pelo processo de conservação da biodiversidade.

\section{NA ÁGUA E NA TERRA: A CONSERVAÇÃO DO TRACAJÁ (Podocnemis unifilis)}

\subsection{ASPECTOS BIOLÓGICOS E ECOLÓGICOS DA ESPÉCIE}

O tracajá, Podocnemis unifilis (Troschel, 1848) pertence ao gênero Podocnemis, família Podocnemididae, ordem Testudine. Essa espécie de quelônio vive nas águas (lagos, rios e igarapés), fazem seus ninhos desde praias arenosas, altas e abertas, até praias baixas, solos areno-argilosos às margens de lagos, barrancos com pouca inclinação, em meio à vegetação arbustiva ou herbácea, e áreas sombrias em solo argiloso na borda da floresta (FERRARA et al., 2016). Trata-se, portanto, de uma espécie menos seletiva para desovar.

Os seus ninhos podem medir até $18 \mathrm{~cm}$ de profundidade. Suas carapaças medem em média $33,6 \mathrm{~cm}$ de comprimento e 7,8 cm de largura. As fêmeas da espécie são maiores que os machos, e pesam de $4 \mathrm{~kg}$ a $7 \mathrm{~kg}$ e $3 \mathrm{~kg}$ respectivamente. As fêmeas depositam em média 12 a 35 ovos que eclodem em aproximadamente 60 dias. A espécie possui a forma ovalada, carapaça gris escura quando molhada, com o plastrão de coloração escura. Apresenta ainda patas curtas e cobertas com pele rugosa, cabeça achatada e cônica, de pequeno tamanho em relação ao corpo (FERRARA et al., 2016).

A espécie possui manchas amareladas na cabeça, na parte dorsal. Os olhos, bastante juntos, são separados por um sulco (DUARTE et al., 2007; ANDRADE et al., 2012b; FERRARA et al., 2016). No período da nidificação, as fêmeas desovam principalmente à noite, em épocas que variam dependendo do local, como, por exemplo, nos meses de junho a agosto, no oeste do Amazonas; de setembro a outubro no Baixo Amazonas; e em novembro no Rio Negro e afluentes (DUARTE et al., 2007; VOGT, 2008).

Os rastros históricos das relações entre quelônios, especificamente o tracajá, e humanos na Amazônia são resgates de momentos quando esses animais podiam ser vistos nas diversas calhas dos rios da região. Essa forma de relação alimentar com quelônios não ocorre apenas na Amazônia, pois envolve tanto a dimensão econômica quanto cultural (DUPRE et al., 2007). De modo particular, os ovos, carne, vísceras, gordura e casco dos quelônios são as partes mais utilizadas pela população local na atualidade e no passado (VAN DIJK et al., 2014; JÚNIOR et al., 2016).

Ao analisar a história da conservação dos quelônios, e não somente do tracajá, é possível perceber que esta é marcada por apontamentos da administração governamental (ANDRADE, 2007; JÚNIOR et al., 2016). Esses fatos geraram conflitos com as populações locais, pois culturalmente as populações amazônicas já faziam uso na alimentação, antes mesmo da chegada dos europeus. 
Mesmo com a alta diversidade de espécies na região, a intensidade da pressão antrópica nas populações de quelônios, pela captura e venda ilegal, colocou as espécies mais conhecidas, Podocnemís expansa, $P$. unifilis, P. sextuberculata, P. erythrocephala e Peltocephalus dumerilianus na categoria ameaçada e vulnerável, de acordo com os critérios da União Internacional para Conservação da Natureza (IUCN, em inglês) (IUCN, 2015).

Na primeira avaliação, ainda na década de 1970, o tracajá foi classificado como Vulnerável (Vulnerable - VU), e atualmente permanece nessa categoria. De acordo com a última lista de espécies em perigo de extinção divulgada pelo Instituto Chico Mendes de Conservação da Biodiversidade (ICMBio) (2014), o tracajá não consta nas categorias em ameaça.

Nesse contexto, surgem diversas iniciativas para conservação desse quelônio. Uma dessas mobilizações conservacionistas é Projeto Pé-de-Pincha (PPP), inicialmente denominado Manejo Sustentável de Tracajás por comunidades do Baixo Amazonas (ANDRADE, 2012a). O projeto iniciou suas atividades em 1999, dentro da Universidade do Amazonas (atual UFAM), pela iniciativa de comunitários do município de Terra Santa no estado do Pará. Os moradores locais constataram a diminuição das populações de quelônios nos lagos da região, uma consequência do uso descontrolado por pescadores que vinham de outras regiões próximas para pescar nos lagos de Terra Santa (VIDAL; COSTA, 2007).

O PPP tem como objetivo geral conservar as populações de quelônios (Podocnemis unifilis, $P$. sextuberculata, P. expansa e P. erythrocephala) do médio Rio Amazonas e Rio Juruá de modo participativo, envolvendo comunidades e instituições locais, mediante a capacitação e o acompanhamento da Universidade Federal do Amazonas (UFAM) (ANDRADE, 2012b; ANDRADE, 2014). Nesse contexto, Vidal e Costa (2007) citam haver uma relação entre os processos de conservação e ações de educação ambiental (EA) constituída por palestras, capacitação de professores e alunos, formação de agentes ambientais voluntários, incentivo ao ecoturismo e organização de cooperativas locais.

O envolvimento dos comunitários é reflexo da abordagem de EA adotada no projeto, pois tem por objetivo integrar as populações locais com os conhecimentos científicos e habilidades técnicas para que possam participar ativamente das diferentes etapas do programa (LIMA et al., 2012). Com isso, o projeto está organizado em dois núcleos: educativo e manejo, nos quais a educação ambiental é o processo que perpassa o desenvolvimento das ações de conservação.

\subsection{CARACTERIZAÇÃO DA CONSERVAÇÃO}

Nesse contexto, a conservação dos tracajás engloba uma rede de pessoas e 6 etapas de manejo (VIDAL; COSTA, 2007): etapa 1) fiscalização, das praias utilizadas para a nidificação pelos quelônios; etapa 2) coleta, mediante a identificação dos ninhos nas praias; etapa 3) transplante, transferência dos ninhos das praias naturais para as artificiais, denominadas "berçários"; etapa 4) eclosão, nascimento dos filhotes e acompanhamento biométrico; etapa 5) maturação, alimentação e acompanhamento biométrico; etapa 6) soltura, quando os tracajás são soltos nas praias onde foram coletados.

Esse encadeamento de etapas é voltado à criação de ambientes de diálogo nas comunidades, sejam nas praias, campos de futebol, nos quintais ou escola locais para envolver os comunitários, professores e estudantes. Esses locais serviram de espaços para integração dos conhecimentos coletivos de forma multi e interdisciplinar (LIMA et al., 2012). Esses espaços de envolvimento e integração fomentaram, na perspectiva do projeto, a busca por ações inovadoras para discussões de questões ambientais locais, indo além dos aspectos ecológicos, tentando atender às dimensões éticas, políticas, sociais, econômicas, científicas, tecnológicas e culturais, ou seja, uma visão integradora.

\subsection{ANÁLISE DAS ATIVIDADES}

Essa estrutura de conservação, em análise, coaduna-se às discussões de Saito et al. (2011) acerca das perspectivas educacionais e sua relevância no reconhecimento, na avaliação e no enfrentamento de problemas de âmbito local ou regional dos conflitos socioambientais. Os autores verificam a 
necessidade de superar certas estratégias educacionais, pois essas são "restritas às perspectivas preservacionistas/ conservacionistas ou biologicistas, que apontam, na maioria das vezes, para perspectivas comportamentalistas e pragmáticas na solução dos problemas ambientais" (SAITO et al., 2011, p. 124).

Os processos educativos pouco inovadores, descontextualizados ou superficiais caminham na contramão do esperado para projetos de conservação e desenvolvimento. Para Ummus (2015, p.117), esses programas de caráter exógeno devem "adotar uma perspectiva sistêmica complexa, tomada a partir do ponto de vista do sistema local e abordando múltiplas dimensões, escalas espaço-temporais e níveis políticos e institucionais".

Dessa forma, a abordagem necessária a um programa de conservação pautado em processos educativos deve ser complexa, integradora e muldimensional. Torna-se necessário compreender que a prática da Educação Ambiental para promover a participação e cidadania ativa perpassa a mobilização consciente, reflexiva e fundamentada nos conhecimentos científicos e nas experiências exitosas (SAITO et al., 2011). Essa lógica embasa, mas não define quais estratégias são infalíveis, pois cada programa desenvolve-se a partir da realidade local.

Nesse contexto, analisando os relatórios de 1999 a 2014, verificou-se que o PPP realiza a conservação a partir de aspectos técnicos do manejo dentro de uma concepção educativa. Dessa forma, os comunitários têm papel decisivo na escolha e realização das atividades, pois todo trabalho é constituído na dimensão do voluntariado. Essa forma de integração entre agentes distintos reflete o manejo do tipo participativo, modo pelo qual os idealizadores do projeto o identificam.

A nomenclatura "participativa" é uma das identificações do co-manejo ou co-gestão, também identificada pelas alcunhas de colaborativa, conjunta, mista ou multipartidária (BORRINI-FEYERRABEND et al., 2001). O aspecto participativo refere-se à reunião de dois ou mais atores sociais (governo, comunidades e comunitários), onde negociam, definem e asseguram entre si divisões das atividades de manejo, direitos e responsabilidades sobre determinado território, área ou conjunto de recursos naturais (BORRINI-FEYRRABEND et al., 2001; PLUMMER; FITZGIBBON, 2004; PLUMMER, 2009; BERKES, 2009). Borrini-Feyerrabend et al. (2001) propõem que os projetos que almejam desenvolver o co-manejo devem atentar para fomentar abordagens relativas à gestão participativa, pluralismo, governança, patrimônio, gestão de conflitos e comunicação social.

No caso do co-manejo organizado para a conservação do tracajá, enquanto processo educativo, identificam-se as abordagens comunicativa, formativa e integração comunitária. Na primeira vê-se a construção de espaços de diálogo e divulgação científica, na segunda têm-se aspectos da educação ambiental, as técnicas do manejo e conservação, e, por fim, na integrativa, constam as atividades lúdicas, treinamento de campo e gincana ecológico-cultural.

A dimensão comunicativa surge como intercâmbio de informação e conhecimento entre os grupos participantes. Essa abordagem é fundamental na organização de iniciativas, na manutenção, organização e planejamento de ações futuras (BORRINI-FEYERRABEND et al., 2001; CRONA; BODIN, 2006). No caso do PPP, a comunicação atua de duas formas: na primeira pela realização de palestras, seminários e reuniões. Nesta, o objetivo é envolver os comunitários nas atividades de manejo a partir das discussões e socializações de questões inerentes ao cotidiano local e integrá-los aos demais comunitários, assim como aos pesquisadores pelo ensino-aprendizagem das técnicas do manejo.

Borrini-Feyerrabend et al. (2001) discutem o fato de que a integração entre comunitários e pesquisadores é uma necessidade, haja vista a compreensão do funcionamento dos sistemas locais de comunicação, o aprender a ouvir, e até mesmo ouvindo o silêncio, pois pode expressar diferentes tipos de mensagens, que podem variar de apoio à hostilidade.

Outra forma refere-se ao aspecto de fomentar "a discussão de problemas, oportunidades e opções alternativas de ação, promovendo condições para que as pessoas tomem decisões de maneira informada" (BORRINI-FEYERRABEND et al., 2001, p. 11). A comunicação comunitário-comunitário também se destaca como um aspecto importante, trata-se de uma tendência presente em grupos 
homogêneos, já que no caso essas pessoas vivem em comunidade e possuem vivências semelhantes (CRONA; BODIN, 2006).

Esses aspectos da comunicação de modo intrapar (comunitário-comunitário) e extrapar (pesquisadorcomunitário) são constituintes da relação social local. Há também a comunicação para fora da comunidade, representada pela divulgação científica. Esse processo de divulgação envolve estratégias voltadas para a comunicação de informações científicas de modo a facilitar o entendimento de determinado tema específico pelo público leigo, em sua maioria, a partir da reformulação do discurso do cientista.

Nessa ação, também identificada na literatura como difusão científica ou popularização da ciência, faz parte da etapa do co-manejo descrita por Carlsson e Berkes (2005) como a "prescrição ou determinação de soluções". Isso significa dizer que a equipe do projeto, ao fim de um ciclo, deve comunicar seus resultados aos outros grupos relevantes, nesse caso, a academia e outros comunitários. Dessa forma, pode contribuir com conhecimento no processo do co-manejo e formulação de políticas para a resolução de problemas futuros, trata-se, portanto, da educação ambiental na sua plenitude.

Se a comunicação é algo explícito dentro do projeto e alinhado à literatura científica como estratégia procedimental, as demais abordagens do co-manejo aparecem diluídas ao longo de suas práticas. A realização de ações voltadas à formação e integração comunitária, nos moldes de suas concepções, é indício da adaptação e flexibilização do manejo. A prática de considerar válida as múltiplas perspectivas e heterogêneas formas de saberes e conhecimentos ecológicos, seja de pesquisadores ou de interessados diretos, ou comunitários, é denominada co-manejo adaptativo (CARLSSON; BERKES, 2005; FENNELL et al., 2008; BERKES, 2004, 2009; CUNDILL; FABRICIUS, 2009).

O co-manejo adaptativo inclui um dispositivo que leva em consideração as experiências locais para construir e mesmo avaliar suas estratégias de ação, o qual é chamado de feedback, gerado pela aprendizagem social (FENNELL et al., 2008). A aprendizagem social é uma das peças constituintes do co-manejo adaptativo, pois é meio e fim do processo.

A materialização da aprendizagem social é traduzida na ação de aprender o manejo, vivenciando-o e fazendo-o (HOLLING, 1978). Essa forma de aprendizagem é processual e opera primeiramente por uma aprendizagem experiencial, na qual o conhecimento é criado pela transformação da experiência e aprendizagem prática. Na sequência, tem-se a aprendizagem transformadora, que é um processo reflexivo a partir das percepções e consciência, por fim, a aprendizagem social completaria o ciclo com reflexões iterativas quando grupos e indivíduos trocam experiências (ARMITAGE et al., 2008).

\section{ESTRUTURAS E PROCESSOS NA CONSERVAÇÃO DA FAUNA SILVESTRE}

As análises sobre os processos educativos como meios de articulação e direcionamento para a conservação da fauna, seja para o tracajá ou o gavião-real, mostram uma heterogeneidade de estratégias de ação, de forma a abarcar a maior quantidade possível de comunitários e outros agentes. Desse modo, verifica-se que o planejamento de uma ação de conservação deve ser pensado a partir das seguintes dimensões:

a) Participativa, na medida em que a conservação e o manejo sejam ações intencionais, uma busca/ necessidade coletiva local e de comum interesse dos comunitários e agentes externos;

b) Colaborativa, em que pese a equivalência dos saberes e conhecimentos dos agentes, internos ou externos no planejamento, execução e avaliação das ações de conservação e co-manejo ou manejo colaborativo;

c) Comunicativa, no sentido de evitar ruídos nos diálogos entre os agentes envolvidos, assim como na criação de espaços que facilitem, favoreçam e potencializem as trocas de ideias, antes e durante o processo de manejo e conservação; 
d) Educativa, pois é a partir do/no processo de ensino-aprendizagem do conhecimento científico que as diversas formas de saberes são discutidas e contextualizadas para sensibilizar e mostrar a importância da conservação e o manejo das espécies em questão, mas também de fomentar a coletividade local e seus interesses comunitários.

Portanto, entende-se que a partir do nível de conhecimento e saber que os comunitários possuem sobre as espécies conservadas, há um desdobramento na forma como se constrói o universo perceptivo sobre determinado animal. De início, há as desmistificações sobre o comportamento da espécie e, segundo, que, ao conhecer a sua função no ambiente, o participante pode desconstruir sua forma de ver o animal. Desse modo, diversificam-se as formas como os animais serão vistos pelos olhos antrópicos, já que serão considerados não apenas os aspectos biológicos, mas também os sociais, culturais, simbólicos, entre outros.

Essas demais formas de considerações nos levam a compreender que, para além do mero domínio humano sobre as espécies não humanas, eles também se apresentam como sujeitos-de-uma-vida (REGAN, 2006; SINGER, 2010), e, desse modo, possuidores do direito a ter direito. Além desses aspectos, somam-se ao contexto das práticas de manejo na região amazônica, questões intersubjetivas da relação entre as sociedades ameríndias e os animais não humanos (DESCOLA, 1998, 2012; VIVEIROS DE CASTRO, 1996, 2013), cujo mundo é permeado de pessoas de outras espécies e demais entidades, que fazem parte da epistemologia indígena. Nesse sentido, Mateus et al. (2018) discutem que o manejo como estratégia de conservação de espécies ameaçadas de extinção pode ser benéfico, mas para que isso ocorra, deve-se enfatizar a relação sensível entre humano e não humano e aglutinar os conhecimentos ecológicos, biológicos e etológicos para dar maior eficiência ao manejo.

No caso do gavião-real, verifica-se que o co-manejo teve efeito a partir do momento que os moradores compreenderam a importância de assumirem as responsabilidades pela conservação da espécie, a partir do seu contexto folclórico e cultural. Já na conservação do tracajá, a aprendizagem social gerada ao longo do período de atividades fomentou nas comunidades uma autonomia e mesmo um controle social das práticas de manejo, o que perpetua-se mesmo na ausência do programa institucional.

\section{REFERÊNCIAS}

ADOM, D. Inclusion of Local People and Their Cultural Practices in Biodiversity Conservation: lessons from successful nations. American Journal of Environmental Protection, v. 4, n. 3, p. 67-78, 2016.

AGUIAR-SILVA, F. H.; SANAIOTTI, T. M. Mapping the home range of harpy eagles in the Brazilian Amazon basin. Argos Forum, v. 6, 2013, p. 4, 2013.

AGUIAR-SILVA, F. H.; SANAIOTTI, T. M.; LUZ, B. B. Food Habits of the Harpy Eagle, a Top Predator from the Amazonian Rainforest Canopy. Journal of Raptor Research, v. 48, n. 1, p. 24-35, 2014.

ANDRADE, P. C. M. (Ed.). Criação e Manejo de Quelônios no Amazonas. Projeto Diagnóstico da Criação de Animais Silvestres no Estado do Amazonas. 2. ed. ProVárzea/Fapeam/SDS. Manaus/AM., 2007. 447 p.

ANDRADE, P. C. M. Assim nasceu o Projeto Pé-de-Pincha! In: ANDRADE, P. C. M. (Org.). Manejo Comunitário de Quelônios no Médio Amazonas e Juruá - Projeto Pé-de-Pincha. Manaus: Gráfica Moderna, p.15-88, 2012a.

O projeto Pé-de-Pincha em números: a conservação comunitária de tracajás (Podocnemis unifilis). In: ANDRADE, P. C. M. (Org.). Manejo Comunitário de Quelônios no Médio Amazonas e Juruá - Projeto Pé-de-Pincha. Manaus: Gráfica Moderna, p. 15-88, 2012b.

. Manejo Comunitário de Quelônios no Médio Rio Amazonas, Negro, Madeira e Juruá Programa Pé-de-Pincha. Relatório Final Geral Barreirinha-AM. Laboratório de Animais Silvestres, Faculdade de Ciências Agrárias, Universidade Federal do Amazonas. Manaus-AM, 2014. 
ARMITAGE, D.; MARSCHKEB, M.; PLUMMER, R. Adaptive co-management and the paradox of learning. Global Environmental Change, v. 18, p. 86-98, 2008.

BANHOS, A. et al. Reduction of Genetic Diversity of the Harpy Eagle in Brazilian Tropical Forests. Plos One, v. 11, n. 2, 12 p., 2016.

BARDIN, L. Análise de conteúdo. Lisboa: Edições Setenta, 2016. 226 p.

BARNOSKY, A. D. et al. Has the Earth's sixth mass extinction already arrived? Nature, v. 471, p. 51-57, Mar., 2011.

BARUA, M. et al. Defining Flagship Uses is Critical for Flagship Selection: a critique of the IUCN climate change flagship fleet. Ambio, v. 40, n. 4, p. 431-435, Jun., 2011.

BERKES, F. Evolution of co-management: role of knowledge generation, bridging organizations and social learning. Journal of Environmental Management, v. 90, p. 1692-1702, 2009.

Rethinking community-based conservation. Conservation Biology, v. 18, n. 3, p. 621-630, 2004.

BICKFORD, D. et al. Science communication for biodiversity conservation. Biological Conservation, v. 151, p. 74-76, 2012.

BORRINI-FEYERABEND, G. et al. Manejo Conjunto de los Recursos Naturales - Organizarse, Negociar y Aprender en la Acción. GTZ y UICN, Kasparek Verlag, Heidelberg (Alemania), 2001.

BOWEN-JONES, E.; ENTWISTLE, A. Identifying appropriate flagship species: the importance of culture and local contexts. FFI, Oryx, v. 36, n. 2, p. 189-195, 2002.

CARLSSON, L.; BERKES, F. Co-management: concepts and methodological implications. Journal of Environmental Management, v. 75, p. 65-76, 2005.

CARO, T. et al. Preliminary assessment of the flagship species concept at a small scale. Animal Conservation, v. 7, p. 63-70, 2004.

CARO, T. M. Conservation by Proxy: indicator, umbrella, keystone, flagship, and other surrogate Species. Island Press: Washington, Covelo, London, 2010.

CARVALHO, R. S.; AGUIAR-SILVA, F. H.; CARMO, C. C. Mostras de Ciências (Itinerante) no Assentamento Vila Amazônia: popularização da Ciência em diferentes espaços educativos. In: X ENCONTRO NACIONAL DE PESQUISA EM EDUCAÇÃO EM CIÊNCIAS, ENPEC. Águas de Lindoia, SP, 24 a 27 de Nov., 2015.

CASTRO, E. V. de. A inconstância da alma selvagem e outros ensaios de antropologia. São Paulo: Cosac \& Naify, 2013.

Os pronomes cosmológicos e o perspectivismo ameríndio. Mana, Rio de Janeiro v. 2, n. 2, p. 115-44, out. 1996.

CLUCAS, B.; MCHUGH, K.; CARO, T. Flagship species on covers of US conservation and nature magazines. Biodiversity Conservation, v. 17, p. 1517-1528, 2008.

CRONA, B.; BODIN, Ö. What you know is who you know? Communication patterns among resource users as a prerequisite for co-management. Ecology and Society, v. 11, n. 27, 2006.

CUNDILL, G.; FABRICIUS, C. Monitoring in adaptive co-management: toward a learning based approach. Journal of Environmental Management, v. 90, p. 3205-3211, 2009.

CURTI, M.; VALDEZ, U. Incorporating Community Education in the Strategy for Harpy Eagle Conservation in Panama. The Journal of Environmental Education, v. 40, n. 4, p. 3-16, 2009. 
DESCOLA, P. Más al lá de naturaleza y cultura. Buenos Aires: Amorrortu, 2012.

Estrutura ou sentimento: a relação com o animal na Amazônia. Mana, Rio de Janeiro, v. 4, n. 1, p. 23-45, abr. 1998.

DIRZO, R. et al. Defaunation no Antropocene. Science, v. 345, n. 6195, p. 401-406, Jul., 2014.

DUARTE, A. M.; COSTA, F. S.; ANDRADE, P. C. M. Revisão sobre as características das principais espécies de quelônios aquáticos amazônicos. In: MACHADO, P. C. (Org.). Criação e manejo de quelônios no Amazonas. Manaus: Ibama, ProVárzea, p. 24-54, 2007.

DUPRE, A.; DEVAUS, B.; BONIN, F. Turtles of the world. London, A \& C Black Plublishers, 2007.

ELLIS, E. C. et al. Dating the Anthropocene: towards an empirical global history of human transformation of the terrestrial biosphere. Elem. Sci. Anth, 2013.

FENNELL, D.; PLUMMER, R.; MARSCHKEC, M. Is adaptive co-management ethical? Journal of Environmental Management, v. 88, p. 62-75, 2008.

FERGUSON-LEES, J.; CHRISTIE, D. A. Raptors of the world. New York: Houghton-Mifflin Company, 2001. $992 \mathrm{p}$.

FERRARA, C. R. et al. História natural e biologia dos quelônios amazônicos. In: BALESTRA, R. A. M. (Org.). Manejo conservacionista e monitoramento populacional de quelônios amazônicos. Instituto Brasileiro do Meio Ambiente e dos Recursos Naturais Renováveis. Brasília: Ibama, p.15-28, 2016.

FREITAS, M. A.; LIMA, D. M.; GOMES, F. B. R. Registro de abate de gaviões-reais Harpia harpyja (Accipitridae) para consumo humano no Maranhão, Brasil. Atualidades Ornitológicas, n. 178, Mar./ Abr., 2014.

GALETTI, M.; DIRZO, R. Ecological and evolutionary consequences of living in a defaunated world. Biological Conservation, v. 163, p. 1-6, 2013.

GASTAL, M. L.; SARAGOUSSI, M. Os instrumentos para a conservação da biodiversidade. In: BENSUSAN, N. (Org.). Seria Melhor mandar ladrilhar? Biodiversidade: como, para que e por quê? 2. ed. São Paulo: Peirópolis, Brasília: Editora Universidade de Brasília, 2008.

GUSMÃO, A. C. et al. Records of the occurrence, nesting, and hunting of the Harpy Eagle (Harpia harpyja) (Aves: Accipitridae) in Rondônia, Southwestern Brazilian Amazonia. Atualidades Ornitológicas, v. 190, Mar./Abr., p. 18-23, 2016.

HARRISON, R. D. et al. Consequences of defaunation for a tropical tree community. Ecology Letters, v. 16, n. 5, p. 687-694, 2013.

HOLLING, C. S. Adaptive Environmental Assessment and Management. London: John Wiley and Sons, 1978.

HOME, R. et al. Selection criteria for flagship species by conservation organizations. Environmental Conservation, v. 36, n. 2, Jun., p. 139-148, 2009.

INSTITUTO CHICO MENDES DE CONSERVAÇÃO DA BIODIVERSIDADE (ICMBio). Roteiro Metodológico para Avaliação do Estado de Conservação das Espécies da Fauna Brasileira. Ministério do Meio Ambiente (MMA), Ag., 2014a.

INSTITUTO CHICO MENDES DE CONSERVAÇÃO DA BIODIVERSIDADE (ICMBio). Portaria N. 444 e 445, de 17 de dezembro de 2014b. Lista de Animais em Extinção. Acesso em: 23 jan. 2015.

INTERNATIONAL UNION FOR CONSERVATION OF NATURE (IUCN). IUCN. Red List. Acesso em: 02 mar. 2015. 
INTERNATIONAL UNION FOR CONSERVATION OF NATURE (IUCN). Bird Life International. Harpia harpyja. The IUCN Red List of Threatened Species, 2016.

JÚNIOR, G. S.; BALESTRA, R. A. M.; LUZ, V. L. F. Breve histórico da conservação dos quelônios amazônicos no Brasil. In: BALESTRA, R. A. M. (Org.). Manejo conservacionista e monitoramento populacional de quelônios amazônicos. Instituto Brasileiro do Meio Ambiente e dos Recursos Naturais Renováveis. Brasília: Ibama, p. 11-14, 2016.

KUGLER, H. Na iminência de uma nova extinção? Instituto Ciências Hoje, Jul., 2014.

LIMA, A. C. et al. Educação Ambiental no contexto do projeto Pé-de-Pincha - Percurso metodológico. In: ANDRADE, P. C. M. (Org.). Manejo Comunitário de Quelônios no Médio Amazonas e Juruá - Projeto Pé-de-Pincha. Manaus: Gráfica Moderna, p. 189-250, 2012.

MATEUS, W. D. et al. Amazônia no Antropoceno: o manejo como relação entre humanos e fauna silvestre. Interações, v. 19, n. 3, p. 487-501, 2018.

MILLER, J. R. Biodiversity conservation and the extinction of experience. Trends in Ecology and Evolution, v. 20, n. 8, Aug., p. 430-434, 2005.

MIRANDA, E. B. P. Conservation implications of harpy eagle Harpia harpyja predation patterns. Endangered Species Research, v. 29, p. 69-79, 2015.

PEREIRA, H. M. et al. Scenarios for Global Biodiversity in the 21st Century. Science, v. 330, n. 6010, p. 1496-1501, Dec., 2010.

PLUMMER, R. The Adaptive Co-Management Process: an initial synthesis of representative models and influential variables. Ecology and Society, v. 14, n. 2, p. 24, 2009.

PLUMMER, R.; FITZGIBBON, J. Co-Management of Natural Resources: a proposed framework. Environmental Management, v. 33, n. 6, p. 876-885, 2004.

PRIMACK, R. B.; RODRIGUES, E. Biologia da conservação. Londrina: Planta, 2001.

REGAN, T. Jaulas vazias: encarando o desafio dos direitos animais. Porto Alegre: Lugano, 2006.

ROBERGE, J.-M.; ANGELSTAM, P. Usefulness of the Umbrella Species Concept as a Conservation Tool. Conservation Biology, v. 18, n. 1, p. 76-85, Feb., 2004.

ROTEMBERG, J. A. et al. An integrated community-based harpy eagle and avian conservation program for the maya mountains massif, Belize. In: RICH, T. D. et al. (Ed.). Tundra to Tropics: Connecting Birds, Habitats and People. Proceedings of the Fourth International Partners in Flight Conference, p. 493-507, 2009.

SAITO, C. H. et al. Conflitos Socioambientais, Educação Ambiental e Participação Social na Gestão Ambiental. Sustentabilidade em Debate, v. 2, n. 1, p. 121-138, Jan/Jun., 2011.

SANAIOTTI, T. M. A majestosa harpia no Brasil. In: ROSA, J. M. Harpia. Belo Horizonte: Nitro, p. 58-89, 2010.

SEDDON, P. J. et al. Reversing defaunation: restoring species in a changing world. Science, v. 345, n. 6195, p. 406-412, Jul., 2014.

SEKERCIOG $`$ LU, Ç. H. Promoting community-based bird monitoring in the tropics: conservation, research, environmental education, capacity-building, and local incomes. Biological Conservation, v. 151, p. 69-73, 2012.

SICK, H. Ornitologia Brasileira. Ed. Nova Fronteira, Rio de Janeiro, 1997. 
SIGRIST, T. Avifauna Brasileira, São Paulo, Editora Avis Brasilis, 600 p., 2009

SILVA, F. H. A.; SANAIOTTI, T. M. Preservação para o ecoturismo do gavião-real. In: IV Mostra de Ciências do Assentamento Vila Amazônia, Livro de Resumo, Parintins, AM, 19-27 de Nov., 2007.

SILVA, A. T. R. A conservação da biodiversidade entre os saberes da tradição e a ciência. Estudos Avançados, v. 29, n. 83, São Paulo, Jan./Apr., p. 233-259, 2015.

SIMBERLOFF, D. Flagships, Umbrellas, and Keystones: is single-species management passé in the landscape era? Biological Conservation, v. 83, n. 3, p. 247-257, 1998.

SINGER, P. Libertação animal. São Paulo: WMF/Martins Fontes, 2010.

SMITH, R. J. et al. Identifying Cinderella species: uncovering mammals with conservation flagship appeal. Conservation Letters, v. 5, n. 3, p. 205-212, 2012.

SOARES, E. S. et al. Plano de ação nacional para a conservação de aves de rapina. Coordenação-Geral de Espécies Ameaçadas. Brasília: ICMBio, 2008. 136 p.

STEFFEN, W.; CRUTZEN, P. J.; MCNEILL, J. R. The Anthropocene: are humans now overwhelming the great forces of nature. Ambio, v. 36, n. 8, p. 614-621, 2007.

TRINCA, C. T.; FERRARI, S. F.; LEES, A. C. Curiosity killed the bird: arbitrary hunting of Harpy Eagles Harpia harpyja on an agricultural frontier in southern Brazilian Amazonia. Cotinga, v. 30, p. 12-15, 2008.

UMMUS, R. E. Diversidade de Respostas Locais a Projetos de Conservação e Desenvolvimento Integrados. Sustentabilidade em Debate, v. 6, n. 2, p. 106-121, mai/ago, 2015.

VAN DIJK, P. P. et al. Turtle Taxonomy Working Group. Turtles of the World. 7th Ed. Annotated Checklist of Taxonomy, Synonymy, Distribution with maps, and Conservation Status. Chelonian Research Monographs, n. 5, v. 7, p. 329-479, 2014.

VARGAS, J. J. G. et al. Estado y distribución actual del Águila arpía (Harpia harpyja) en Centro y Sur América. Ornitologia Neotropical, v. 17, p. 39-55, 2006.

VERÍSSIMO, D. et al. Birds as tourism flagship species: a case study of tropical islands. Animal Conservation, v. 12, p. 549-558, 2009.

VIDAL, M. D.; COSTA, T. V. da. Manejo comunitário de quelônios: a parceria ProVárzea/lbama - Péde-Pincha. In: MACHADO, P. C. (Org.). Criação e manejo de quelônios no Amazonas. Manaus: Ibama, ProVárzea, 2007.

VOGT, R. C. Tartarugas da Amazônia. Lima, Peru, 2008. 104 p.

WALPOLE, M. J.; LEADER-WILLIAMS, N. Tourism and flagship species in conservation. Biodiversity and Conservation, v. 11, p. 543-547, 2002.

WORLD WIDE FUND FOR NATURE. How many species are we losing? Disponível em: <http://wwf. panda.org/about_our_earth/biodiversity/biodiversity/>.

WORLD WIDE FUND FOR NATURE. Relatório Planeta Vivo 2014: América Latina passa por grande perda de biodiversidade, mas busca soluções para reverter cenário. 2014. Disponível em: <http://wwf.panda. org/>. 